\title{
Effects of the Hot Alignment of a Power Unit on Oil-Whip Instability Phenomena
}

\author{
A. Vania and P. Pennacchi \\ Politecnico di Milano, Dipartimento di Meccanica, Via La Masa, 1, 20156 Milano, Italy \\ Correspondence should be addressed to P. Pennacchi, paolo.pennacchi@polimi.it
}

Received 9 April 2010; Accepted 29 July 2010

Academic Editor: Jerzy Sawicki

Copyright ( $) 2010$ A. Vania and P. Pennacchi. This is an open access article distributed under the Creative Commons Attribution License, which permits unrestricted use, distribution, and reproduction in any medium, provided the original work is properly cited.

\begin{abstract}
This paper shows the results of the analysis of the dynamic behaviour of a power unit, whose shaft-train alignment was significantly influenced by the machine thermal state, that was affected in operating condition by high subsynchronous vibrations caused by oil-whip instability phenomena. The dynamic stiffness coefficients of the oil-film journal bearings of the generator were evaluated considering the critical average journal positions that caused the instability onsets. By including these bearing coefficients in a mathematical model of the fully assembled machine, the real part of the eigenvalue associated with the first balance resonance of the generator rotor became positive. This paper shows the successful results obtained by combining diagnostic techniques based on mathematical models of journal bearings and shaft train with detailed analyses of monitoring data aimed to investigate the effects of the hot alignment of rotating machines on the occurrence of oil-whip instability onsets.
\end{abstract}

\section{Introduction}

The oil-whip instability phenomenon is one of the most important malfunctions that cause subharmonic components in the frequency spectrum of rotating machine vibrations [1-3]. The destabilising forces that are generated in the oil-film of one or more journal bearings of a shafttrain can induce very high vibration levels and instability phenomena [4-6]. In general, the harmonic order of oilwhirl subsynchronous vibrations is close to $0.5 \times$ revolution $(0.5 X)$ [7-9]. However, when the shaft rotational speed is twice higher than the first flexural critical speed of the rotor, the frequency of the dominant subharmonic component of the shaft vibrations can be synchronised with that of the first flexural critical speed [10-12].

This paper presents an original model-based analysis, developed by the authors, of a case study in which the vibrations of the generator of a $320 \mathrm{KVA}$ power unit measured in operating condition showed a very high subharmonic component whose order was significantly lower than $0.5 \mathrm{X}$ and rather close to that associated with the first balance resonance of the rotor. The authors perform the comparison between the experimental average centreline curve, measured on the generator journal bearing at which the shaft showed the highest vibration levels, and the respective theoretical centreline curve, obtained by integrating the Reynolds equation and considering the nominal bearing load due to the reference hot alignment of the shaft-train defined by the machine manufacturer.

This study showed that in some operating conditions, depending on the machine thermal state, the experimental average journal position was abnormal. Likely this was due to a significant decrease of the bearing load caused by a change of the machine hot alignment.

The analysis of the monitoring data showed that the unstable subsynchronous vibrations were automatically extinguished or generated depending on the average journal position, within the generator bearings, which changed in time on the basis of the machine alignment and thermal state. With regard to this, the machine temperature appeared to be influenced by the air temperature of the cabinet that contained the unit as well as by daily changes of the external temperature, whose highest values were often considerable in summertime. 


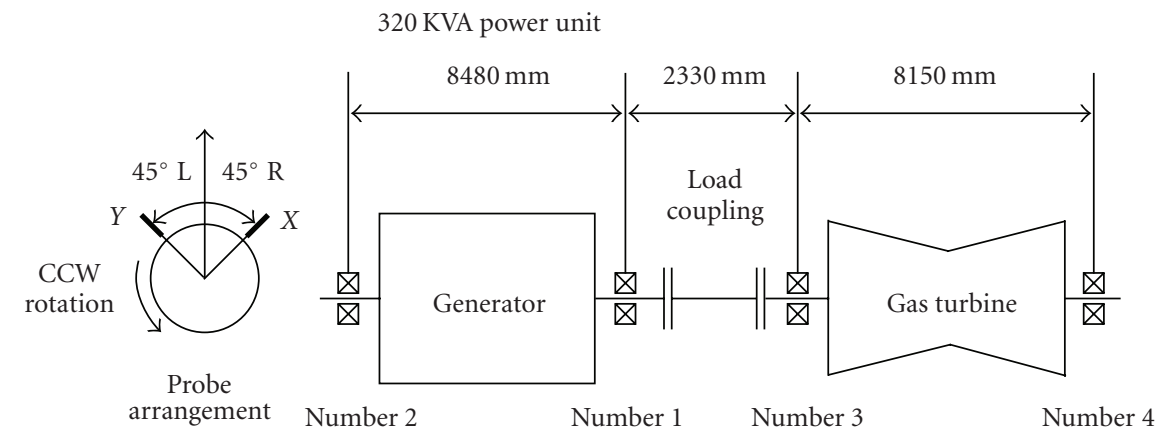

FIgURE 1: Machine-train diagram of the power unit, bearing numbers, and probe arrangement.
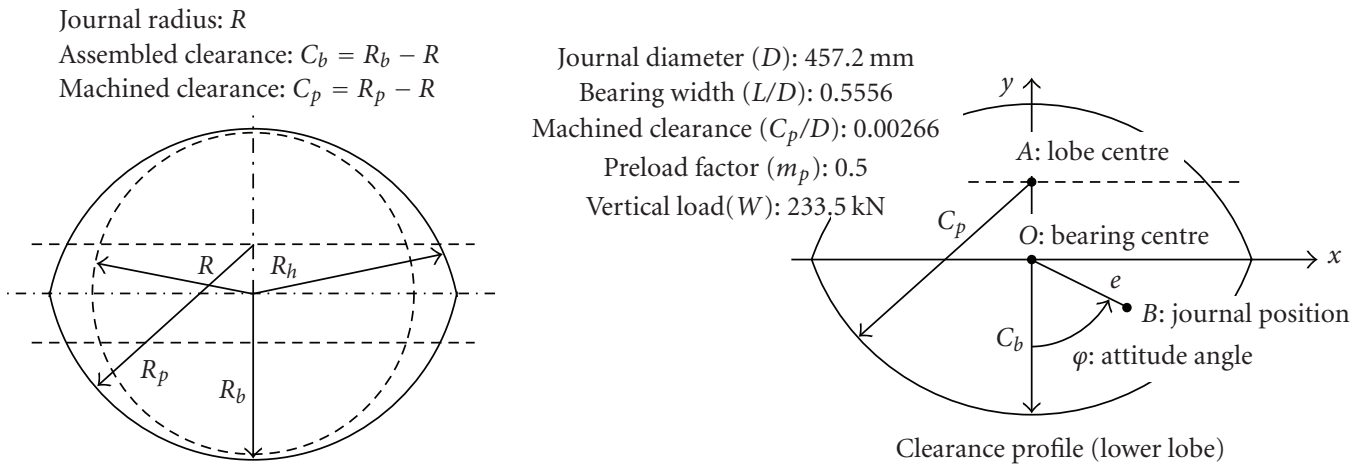

FIGURE 2: Basic geometric parameters of the elliptical journal bearing no. 1.

The dynamic stiffness coefficients of the oil-film associated with different experimental average journal positions were evaluated by means of a bearing model. These coefficients were included into a further mathematical model of the fully assembled rotating machine in order to perform a parametric analysis. The results of this investigation showed that the bearing coefficients, evaluated considering the experimental average journal positions that induced unstable subsynchronous vibrations, caused a positive real part of the eigenvalue of the machine-train model associated with the first flexural critical speed of the generator rotor. This is a basic mathematical condition for the generation of unstable vibrations. Moreover, the first critical speed of the generator evaluated at the operating rotational speed, that is considering the proper estimates of the bearing coefficients that corresponded to the critical hot alignment of the shaft-train, was very close to the rotational speed associated with the frequency order of the subharmonic unstable vibrations experienced in operating conditions. This experimental evidence confirmed the reliability of the results obtained by the authors' study.

In order to develop a more general procedure for the investigation of these phenomena that occasionally affect the dynamic behaviour of rotating machines, the authors present further model-based methods that are used to study the sensitivity of the unstable vibrations to the average journal position inside the generator bearings.

In the end, the analysis of the historic trend of the available monitoring data showed that the instability onsets occurred when the experimental values of the temperature of the white metal of the bearing lower lobe decreased below $81^{\circ} \mathrm{C}$. This allowed incipient occurrences of oil-whip instability phenomena to be timely predicted by the direct analysis of a single parameter, that is, the bearing temperature, that was continuously measured by the condition monitoring system permanently installed in the plant. This diagnostic strategy allowed safety operating conditions of the power unit to be assured, before doing suitable changes of the machine static alignment that were planned within a future scheduled maintenance.

This paper shows the successful results obtained by combining diagnostic techniques, based on models of journal bearings and of shaft-train, with detailed analyses of raw monitoring data, in order to investigate the effects of thermally induced changes in the shaft-train alignment on the generation of oil-whip instability onsets in rotating machines.

\section{Case Study}

The machine-train was composed of a gas turbine and a generator, connected by means of a load coupling. Figure 1 shows the machine-train diagram along with some basic geometrical parameters of the shafts. Further detailed technical information cannot be included in the paper because they are confidential data. The operating rotational speed was $3000 \mathrm{rpm}$. The generator rotor was mounted on two elliptical oil-film journal bearings. Each support was equipped with 


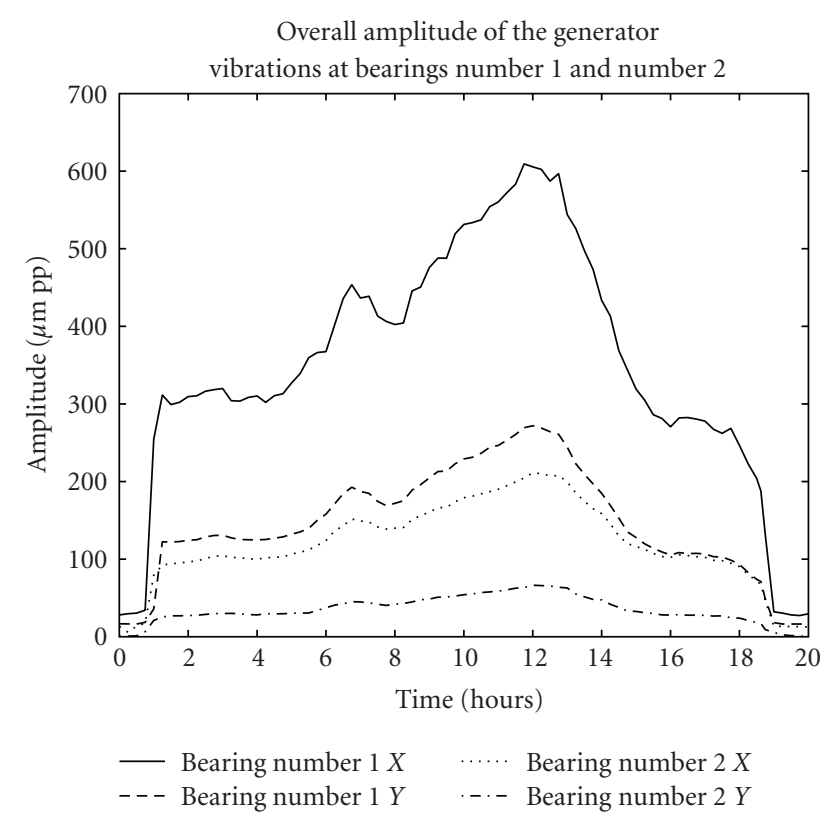

FIgURE 3: Historic trend of the overall amplitude of the vibrations measured at the generator bearings no. 1 and no. 2 in onload operating conditions $(3000 \mathrm{rpm})$ within a twenty-hour time interval.

$X Y$ proximity probes, mounted $90^{\circ}$ degrees apart, that measured the relative shaft-support vibrations.

The inboard generator bearing no. 1, whose basic geometrical parameters are shown in Figure 2, was considered for detailed studies. The vertical bearing load evaluated taking into account that the ideal machine alignment was $233.5 \mathrm{kN}$. Let us denote by $C_{p}$ and $C_{b}$ the machined and assembled radial clearance of the bearing lobes, respectively, while $e$ is the journal eccentricity. The preload factor, $m_{p}$, and the journal eccentricity ratio, $\chi$, are defined as

$$
m_{p}=1-\frac{C_{b}}{C_{p}}, \quad \chi=\frac{e}{C_{b}} .
$$

Owing to the significant preload factor of the generator bearings no. 1 and no. 2, the effective radial clearance evaluated in the horizontal direction was significantly larger than that available in the vertical direction.

The vibration data collected during a seven-month period did not show any significant symptom of malfunction. In particular, the levels of the generator vibrations measured at the operating rotational speed were lower than $40 \mu \mathrm{m}$ pp. Suddenly, during the on-load operating condition, the overall amplitude of the shaft vibrations measured by both pairs of $X Y$ proximity probes mounted on the two journal bearings of the generator significantly raised very quickly (see Figure 3). After few minutes, the maximum vibration level measured at the inboard bearing no. 1 reached $300 \mu \mathrm{m}$ pp.

Although the amplitude of the shaft vibrations relative to the supports was considerable, the absolute vibrations of the bearing casings, measured in the vertical direction by seismic sensors, did not exceed the limit level for the
TABle 1: Amplitude of the most important harmonic orders of the vibrations measured at the generator bearing no. 1 during an instability onset.

\begin{tabular}{lcccc}
\hline & \multicolumn{4}{c}{ Harmonic Orders } \\
Direction & $0.26 \mathrm{X}$ & $0.5 \mathrm{X}$ & $1 \mathrm{X}$ & $2 \mathrm{X}$ \\
\hline$X\left(45^{\circ}\right.$ Right $)$ & $557.1 \mu \mathrm{m} \mathrm{pp}$ & $13.8 \mu \mathrm{m} \mathrm{pp}$ & $31.8 \mu \mathrm{m} \mathrm{pp}$ & $8.3 \mu \mathrm{m} \mathrm{pp}$ \\
$Y\left(45^{\circ}\right.$ Left $)$ & $208.6 \mu \mathrm{m} \mathrm{pp}$ & $23.7 \mu \mathrm{m} \mathrm{pp}$ & $26.5 \mu \mathrm{m} \mathrm{pp}$ & $11.8 \mu \mathrm{m} \mathrm{pp}$ \\
\hline
\end{tabular}

machine trip. Therefore, the unit continued to be operated in on-load condition. After a temporary three hours' dwell of the level rise, the vibration amplitude showed a further considerable increase. In few hours it reached $616 \mu \mathrm{m}$ pp at the measurement point located on the generator bearing no. 1 , oriented in the $X$ direction ( $45^{\circ}$ Right).

The considerable changes in the overall amplitude of the generator vibrations illustrated in Figure 3 did not show any relationship with the unit megawatt load. Some hours after the occurrence of this machine malfunction, the levels of the generator vibrations significantly decreased and in the end they reached the original values lower than $40 \mu \mathrm{m}$ pp once again.

Moreover, the overall amplitude of these vibrations suddenly raised and decreased, after some hours, with nearly the same rate apart from the load value.

The harmonic content of the generator vibrations measured during the most critical stage of the malfunction was evaluated. The most remarkable levels of the shaft vibrations were mainly caused by a subsynchronous harmonic component whose frequency was very close to $13 \mathrm{~Hz}$, that is $0.26 \times$ revolution $(0.26 \mathrm{X})$. When the abnormal dynamic behaviour of the generator was present, the frequency of this subsynchronous vibration was nearly constant. Table 1 shows the amplitude of the most significant harmonic components of the vibration signals provided by the $X Y$ proximity probes mounted on the generator bearings no. 1 and no. 2 when the overall amplitude curves illustrated in Figure 3 reached the highest levels. The amplitude of the $0.26 \mathrm{X}$ vibrations was significantly higher than that of any other order.

Figure 4 shows the timebase plots of the vibration signals measured at the generator bearing no. 1 in the $X$ and $Y$ directions within a time window whose length corresponds to eight complete revolutions of the shaft: this is documented by the eight keyphasor marks reported on the curves of the vibration signals. In the same figure, the experimental vibrations are compared to the regenerated data obtained in the time domain by summing the contributions of the four harmonic components reported in Table 1, associated with the orders $0.26 \mathrm{X}, 0.5 \mathrm{X}, 1 \mathrm{X}$, and $2 \mathrm{X}$. The very small error between experimental and regenerated data confirms that, in occasion of the events of the abnormal dynamic behaviour of the unit, the subsynchronous component at $13 \mathrm{~Hz}$ gave the predominant contribution to the shaft vibrations.

In Figure 5, the unfiltered dimensionless orbit measured at bearing no. 1 within a time interval whose length corresponded to four shaft revolutions, as documented by the presence of four keyphasor markers, is compared to that 


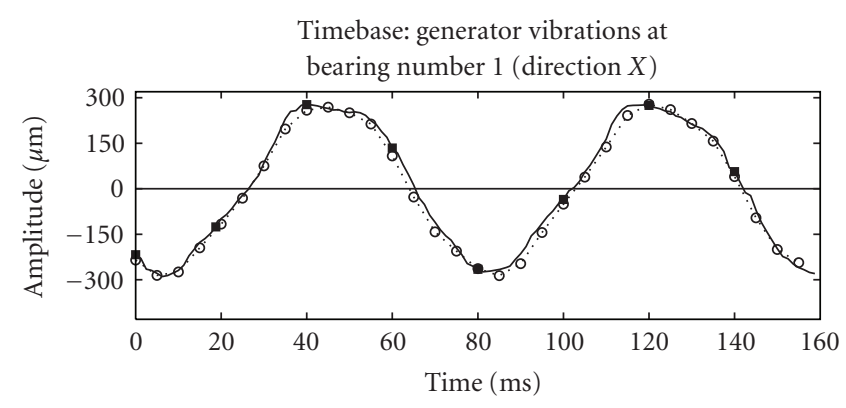

- Keyphasor marker

- Experimental data

.... Regenerated data

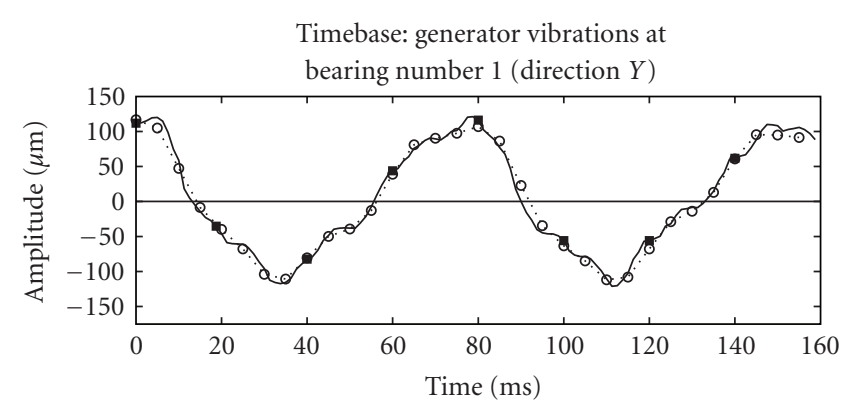

- Keyphasor marker

—o.. Experimental data

FIgURE 4: Comparison between the experimental vibration signal measured at bearing no. 1 in the $X$ and $Y$ directions, during an instability onset, and the respective regenerated signals obtained considering the harmonic orders $0.26 \mathrm{X}, 0.5 \mathrm{X}, 1 \mathrm{X}$, and $2 \mathrm{X}$ reported in Table 1 .

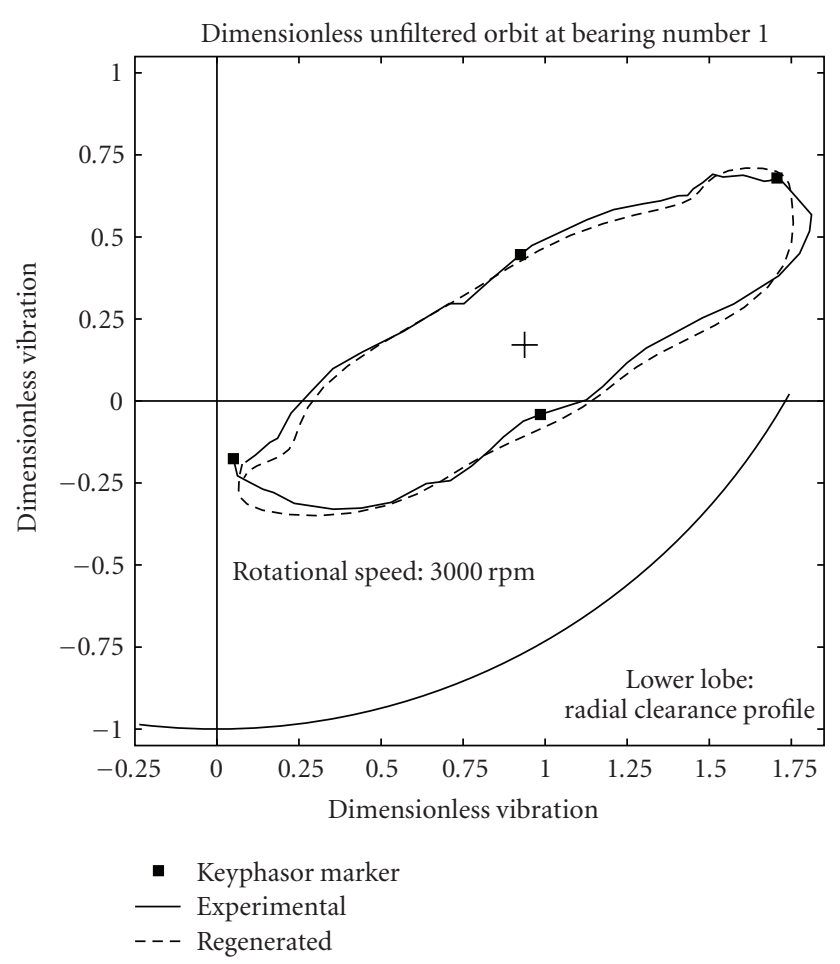

FIGURE 5: Dimensionless journal orbit measured at bearing no. 1 during an instability onset.

obtained considering the four above-mentioned orders of the journal vibration.

These dimensionless orbits have been evaluated dividing the vibration levels by the assembled radial clearance $C_{b}$. The position of the orbit centre was determined considering the average value of the gap data measured by means of the $X Y$ proximity probes within a limited number of shaft revolutions. In the same figure, the contour of the dimensionless region delimited by the machined radial clearance $C_{p}$ of the lower lobe is shown. Owing to the considerable amplitude of the $0.26 \mathrm{X}$ vibrations and the high anisotropy of the oil-film journal bearing, the shape of the unfiltered orbit is nearly elliptical, while its flatness is significant. In fact, the ratio between the minor and major axes of the $0.26 \mathrm{X}$ filtered orbit was 0.2601 . Moreover, the orientation of the major principal axis of this orbit was about $30^{\circ}$ degrees with respect to the horizontal axis. In the end, the average position of the journal, that is the orbit centre, was in the upper part of the bearing.

The elliptical shape of this unfiltered orbit, the particular average position of the journal, as well as the large preload factor $m_{p}$ of the elliptical bearing allowed shaft-to-bearing contacts to be avoided. This was confirmed by a visual inspection of the bearings carried out during subsequent planned maintenance activities (see Figure 6). Before the occurrence of this abnormal dynamic behaviour, the generator vibrations were mainly influenced by the contribution of the $1 \mathrm{X}$ synchronous harmonic component whose low level showed that the residual unbalance of the rotor was rather small. This was confirmed also by the low amplitude of the $1 \mathrm{X}$ vibration vectors measured during several startups and rundowns of the power unit. With regard to this, Figure 7 shows the Bode plot of the $1 \mathrm{X}$ vibrations measured at bearings no. 1 and no. 2 during a machine startup. In the rotational speed range from $750 \mathrm{rpm}$ to $1200 \mathrm{rpm}$, the resonance peaks of the $1 \mathrm{X}$ vibration amplitude due to the passing through some flexural critical speeds of the shafttrain are evident.

\section{Model-Based Diagnostic Analysis}

In order to distinguish the critical speeds of the generator from those of the gas turbine as well as to study the stability of the rotor system, a mathematical model of the fully assembled machine was used. These investigations were performed by means of well-known model-based techniques $[13,14]$. A Finite Element Model (FEM) composed of beam FEs was used to describe the mechanical properties of the shaft-train while the dynamic effects caused by the oilfilm journal bearings were modelled by means of dynamic stiffness coefficients, which depended on the shaft rotational speed. In the end, the bearing pedestals were modelled by 


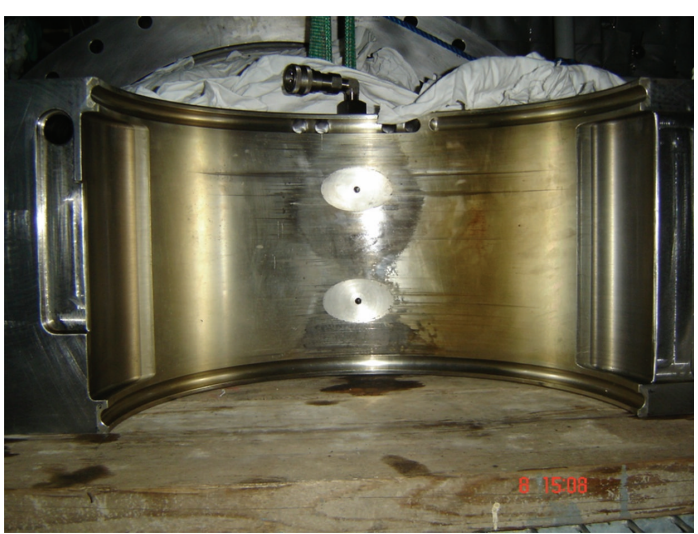

(a)

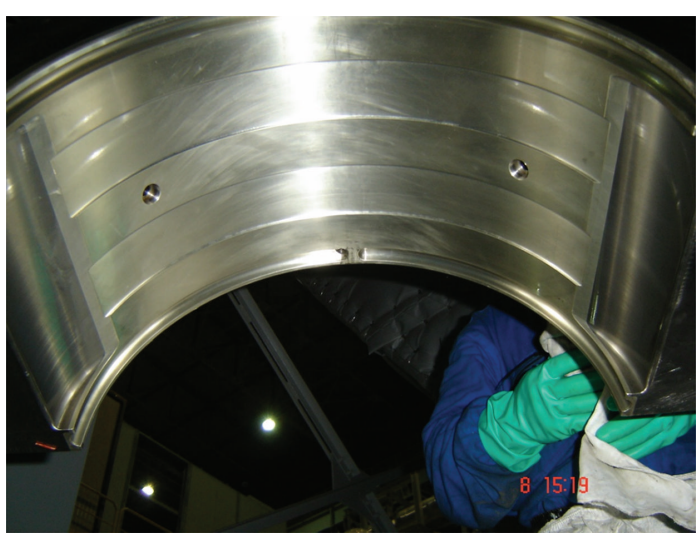

(b)

FIgURE 6: Visual inspection of bearing no. 1: (a) lower lobe and (b) upper lobe.
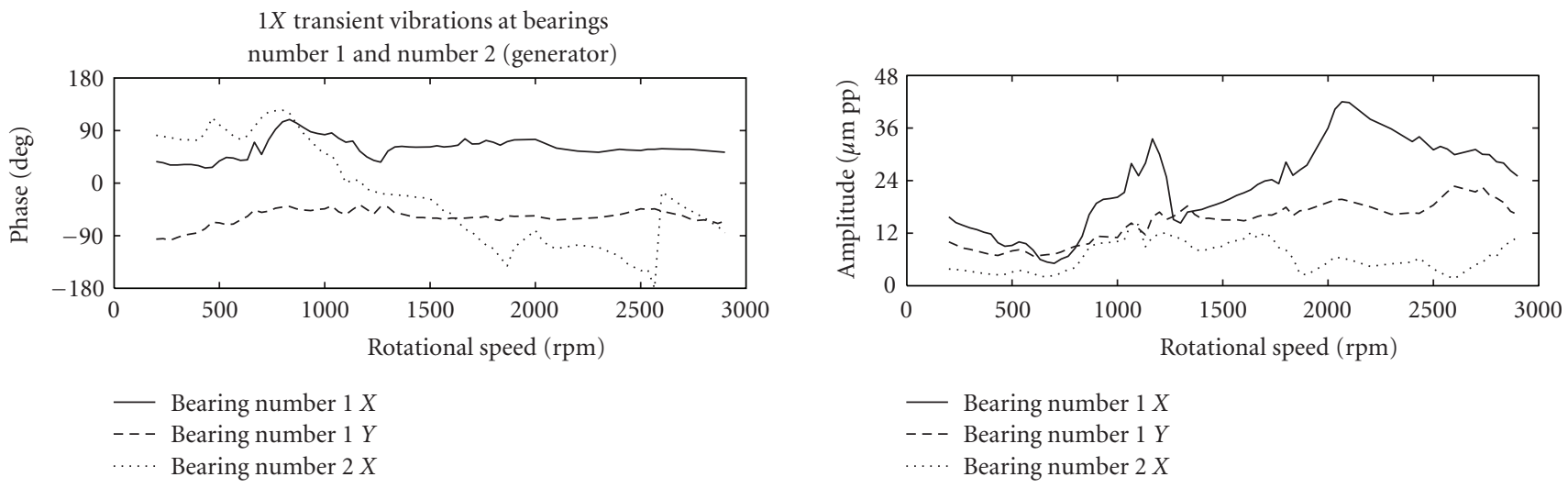

FiguRE 7: Experimental 1X transient vibrations of the generator measured at bearings no. 1 and no. 2 .

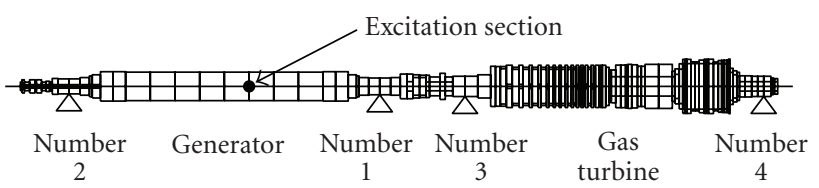

Figure 8: Finite Element model of the shaft-train.

means of a set of simple mechanical systems, having only two degrees of freedom, described using lumped parameters $[13,14]$.

The equation of motion of the rotating machine can be expressed as

$$
[\mathbf{M}] \ddot{\mathbf{x}}+([\mathbf{C}]+\Omega[\mathbf{G}]) \dot{\mathbf{x}}+[\mathbf{K}] \mathbf{x}=\mathbf{F},
$$

where $\Omega$ is the shaft-train angular speed, $\mathbf{x}$ is the vector that contains the displacements and rotations associated with the degrees of freedoms of shafts, bearings and foundation, while $\mathbf{F}$ is the vector that contains the excitations applied to the rotor system. The mass, stiffness, and damping matrices $[\mathbf{M}],[\mathbf{K}]$, and $[\mathbf{C}]$ describe the dynamic effects of the whole rotating machine, while the matrix $[\mathbf{G}]$ takes into account the gyroscopic effects of the shaft-train.
The analysis of the eigenvalues of the machine model can be used to determine the conditions that must be satisfied for the occurrence of unstable vibrations. The $k$ th complex eigenvalue of the model can be written as

$$
\lambda_{k}=\sigma_{k}+i 2 \pi f_{d k}
$$

where $f_{d k}$ is the $k$ th damped natural frequency of the system while $\sigma k$ is the respective modal damping factor. The corresponding undamped natural frequency is given by

$$
f_{n k}=\frac{1}{2 \pi} \sqrt{\left(2 \pi f_{d k}\right)^{2}+\sigma_{k}^{2}} \text {. }
$$

The $k$ th dimensionless modal damping factor, $h_{k}$, can be expressed in the following form:

$$
h_{k}=-\frac{\sigma_{k}}{\left(2 \pi f_{n k}\right)} \text {. }
$$

In order to generate dissipative forces, the dimensionless damping factor $h_{k}$ must be positive, that is, the real part $\sigma_{k}$ of the eigenvalue must be negative. If the normal mode associated with the $k$ th eigenvalue of the machine model is dominated by the lateral vibrations of the shaft-train, the 


\section{(x)}
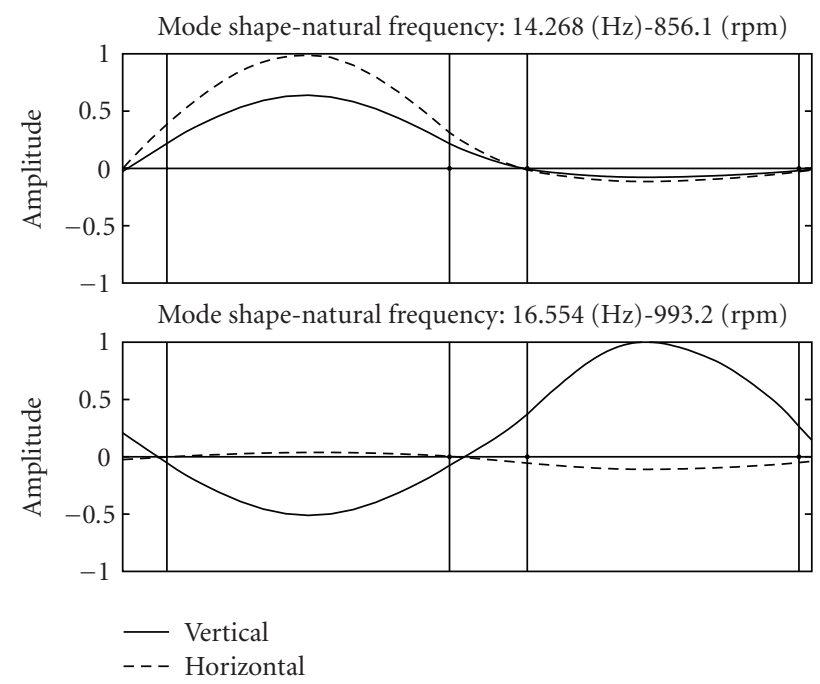
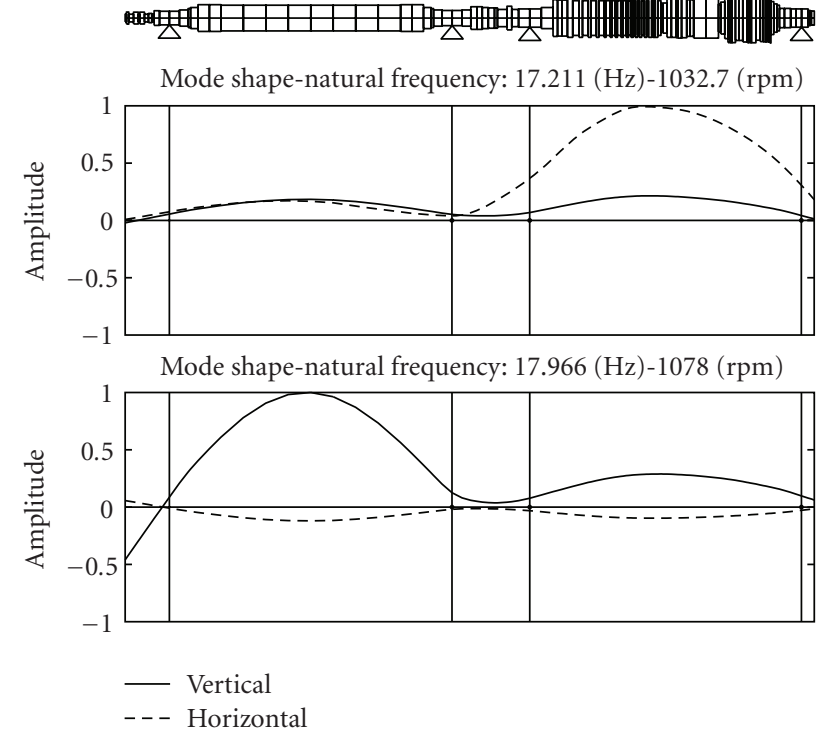

FIgURE 9: Mode shapes of the shaft-train associated with the first four eigenfrequencies evaluated by means of the model no. 2.

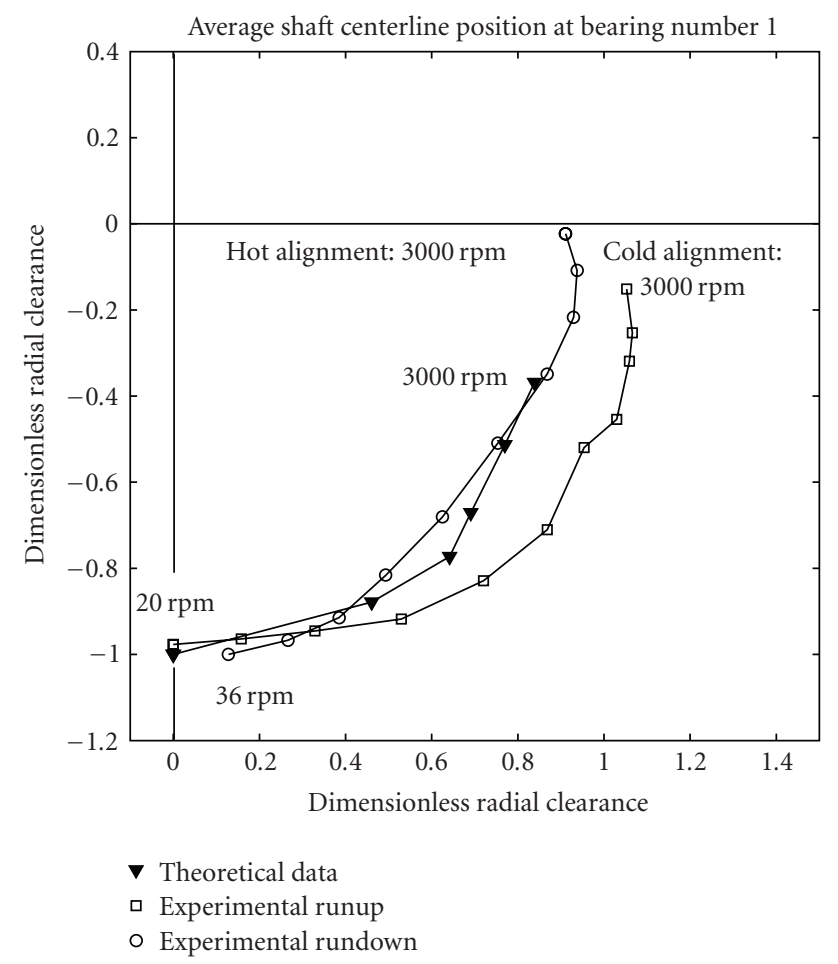

Figure 10: Average journal centreline curve at bearing no. 1: numerical results and experimental data measured in cold and hot thermal states (startup and rundown).

corresponding flexural critical speed, $n_{k}$, can be obtained on the basis of the imaginary part of $\lambda_{k}$ as $n_{k}=60 f_{d k}$.

Owing to the gyroscopic effects and the dependence of the journal bearing coefficients on the rotational speed also the eigenvalues of the machine model are influenced by the shaft speed $\Omega$. Figure 8 shows the Finite Element
TABLE 2: Dimensionless stiffness coefficients of the oil-film journal bearing no. 1, evaluated at $3000 \mathrm{rpm}$, included in the models no. 1, no. 2 , and no. 3 ( $y$ : vertical direction, $x$ : horizontal direction).

\begin{tabular}{lcccc}
\hline & \multicolumn{4}{c}{ Journal bearing no. 1 } \\
& \multicolumn{4}{c}{ Dimensionless stiffness coefficients } \\
Model no. & $K_{y y}$ & $K_{y x}$ & $K_{x y}$ & $K_{x x}$ \\
\hline 1 & 18.2270 & -10.0358 & -1.72375 & 3.1715 \\
2 & 14.2846 & -8.6062 & -0.9748 & 3.2153 \\
3 & 2.7263 & -2.7366 & 0.0158 & 1.3885 \\
\hline
\end{tabular}

Model of the shaft-train whose dynamic behaviour has been investigated in the present case study. A first model of the fully assembled machine, further on denoted model no. 1, included the dynamic stiffness coefficients of the bearings, that is, the stiffness and damping linearised coefficients of the oil-film journal bearings, provided by the machine manufacturer.

The dynamic stiffness coefficients of bearing no. 1 only were evaluated also by means of a computer code developed by the authors on the basis of a well-known theory [15-18]. These coefficients, which showed to be in good accordance with those provided by the machine manufacturer, were included into a further model hereinafter denoted no. 2 . The dimensionless stiffness coefficients of bearing no. 1 included in the models no. 1 and no. 2, as well as those included in a further model denoted no. 3 whose characteristics are described in the following, are reported in Table 2.

The eigenvalues of the models no. 1 and no. 2 associated with the operating rotational speed of the unit $(3000 \mathrm{rpm})$ were evaluated. The imaginary part of the eigenvalues gave an estimate of flexural critical speeds of the shaft-train in the running state, while the respective real part of the eigenvalues allowed the dimensionless modal damping factors, $h$, to be determined in accordance with (5). 

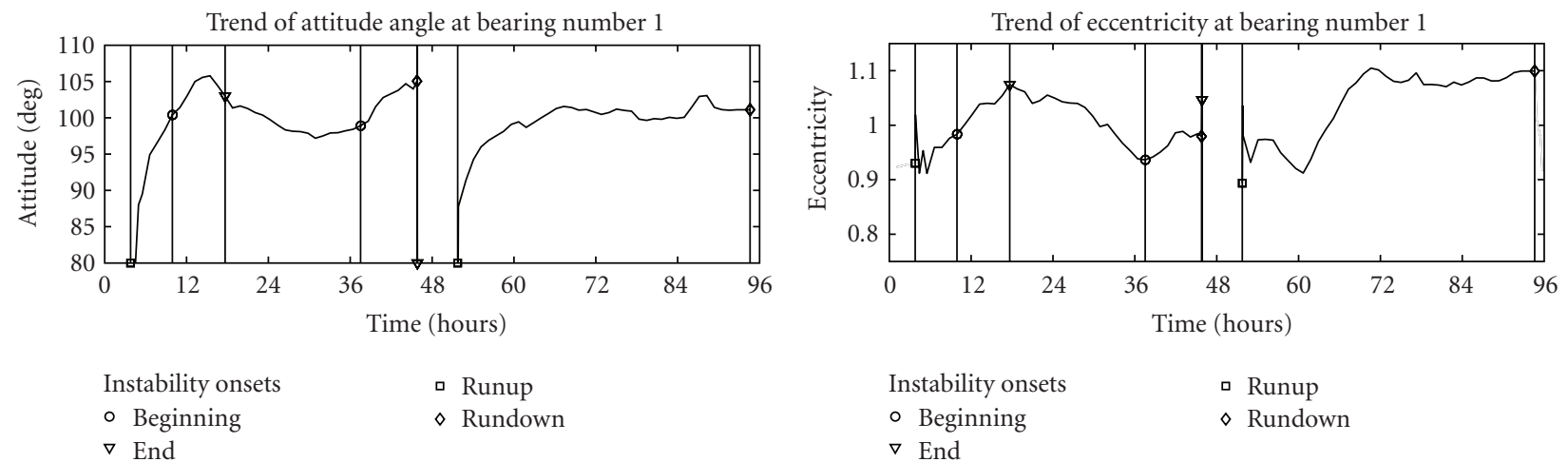

FIGURE 11: Dimensionless eccentricity and attitude angle of the journal of bearing no. 1 measured during a time interval within which two instability onsets occurred.

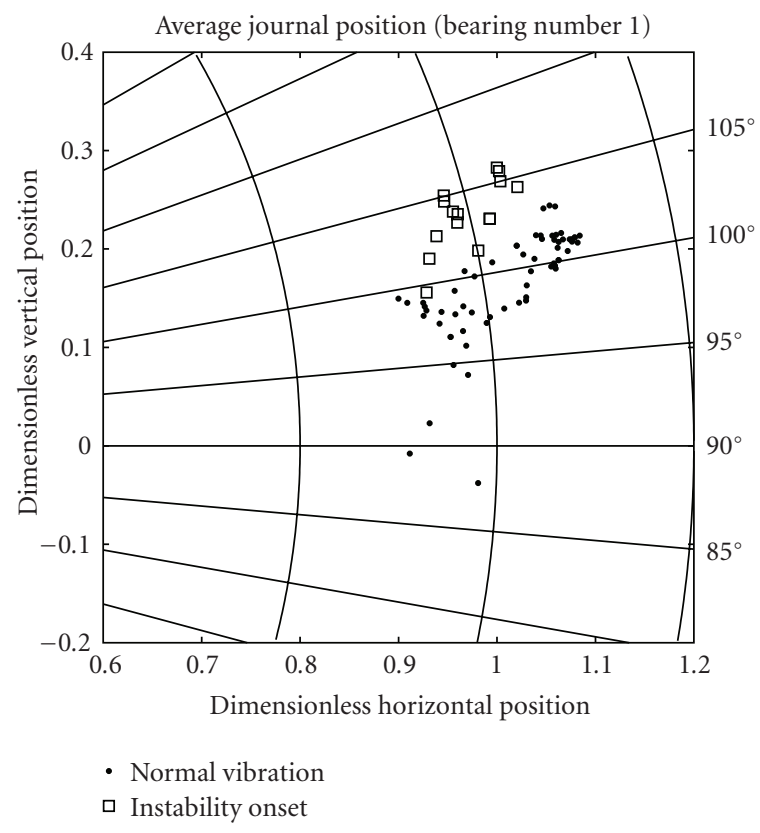

Figure 12: Polar plot of the dimensionless journal position of bearing no. 1 measured during a four-day time interval within which two oil-whip instability onsets occurred.

Table 3 shows the first five flexural critical speeds of the shaft-train along with the respective dimensionless damping factors. In this table, also the results provided by the model no. 3, described in the following, are shown. The results obtained with both models no. 1 and no. 2 are in good accordance with each other. The first flexural critical speed, close to $845 \mathrm{rpm}$, is associated with the first " $U$ " normal mode of the generator rotor. Owing to the significant anisotropy of the elliptical journal bearings no. 1 and no. 2 , the shape of the corresponding normal mode is mainly affected by lateral vibrations contained in the horizontal plane. Nevertheless, the generator vertical vibrations of this normal mode are not negligible (see Figure 9). These results are in good accordance with the experimental evidence.

It is necessary to consider that the imaginary part of the model eigenvalues evaluated considering the operating speed

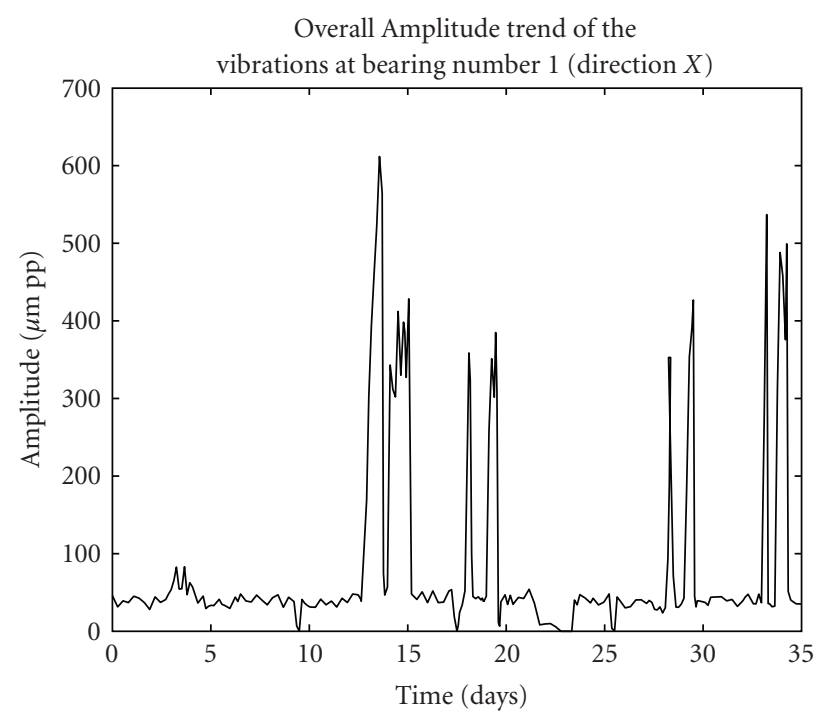

FIGURE 13: Historic trend of the overall amplitude of the generator vibrations measured at bearing no. 1 during a 35-day period.

(3000 rpm) is influenced by the speed dependent values of the dynamic stiffness coefficients of the oil-film journal bearings. In general, the increase of the shaft rotational speed causes a decrease of the direct terms of the oil-film stiffness. Therefore, the values of the lowest flexural critical speeds of a rotor tend to decrease when they are evaluated for increasing values of the rotational speed.

Moreover, both models no. 1 and no. 2 showed that the dimensionless damping factor associated with the first flexural critical speed of the generator rotor was positive; however, its value was rather small.

The oil-whirl phenomenon is one of the most important malfunctions that cause the presence of subharmonic components in the frequency spectrum of rotating machine vibrations [18]. In this case, the destabilising forces that are generated in the oil-film of one or more journal bearings of the shaft-train can induce very high vibration levels and instability phenomena. In general, owing to the value of the average circumferential angular velocity of the fluid 
TABle 3: First five flexural critical speeds and dimensionless modal damping factors of the machine-train evaluated at $3000 \mathrm{rpm}$ by means of the models no. 1 , no. 2 , and no. 3 .

\begin{tabular}{lcccccc}
\hline & \multicolumn{2}{c}{ Model no. 1 } & \multicolumn{2}{c}{ Model no. 2 } & \multicolumn{2}{c}{ Model no. 3 } \\
No. & $\begin{array}{c}\text { Flexural critical speed } \\
(\mathrm{rpm})\end{array}$ & $\begin{array}{c}\text { Damping factor } \\
\text { dimensionless }\end{array}$ & $\begin{array}{c}\text { Flexural critical speed } \\
(\mathrm{rpm})\end{array}$ & $\begin{array}{c}\text { Damping factor } \\
\text { dimensionless }\end{array}$ & $\begin{array}{c}\text { Flexural critical speed } \\
(\mathrm{rpm})\end{array}$ & $\begin{array}{c}\text { Damping factor } \\
\text { dimensionless }\end{array}$ \\
\hline 1 & 842.9 & 0.01185 & 856.1 & 0.00886 & 798.4 & -0.00777 \\
2 & 993.8 & 0.02088 & 993.3 & 0.02044 & 963.2 & 0.03806 \\
3 & 1033.4 & 0.02856 & 1032.7 & 0.02901 & 1007.5 & 0.03301 \\
4 & 1082.4 & 0.00856 & 1078.0 & 0.01130 & 1043.7 & 0.02681 \\
5 & 2059.9 & 0.06189 & 2105.3 & 0.05499 & 1938.2 & 0.03850 \\
\hline
\end{tabular}

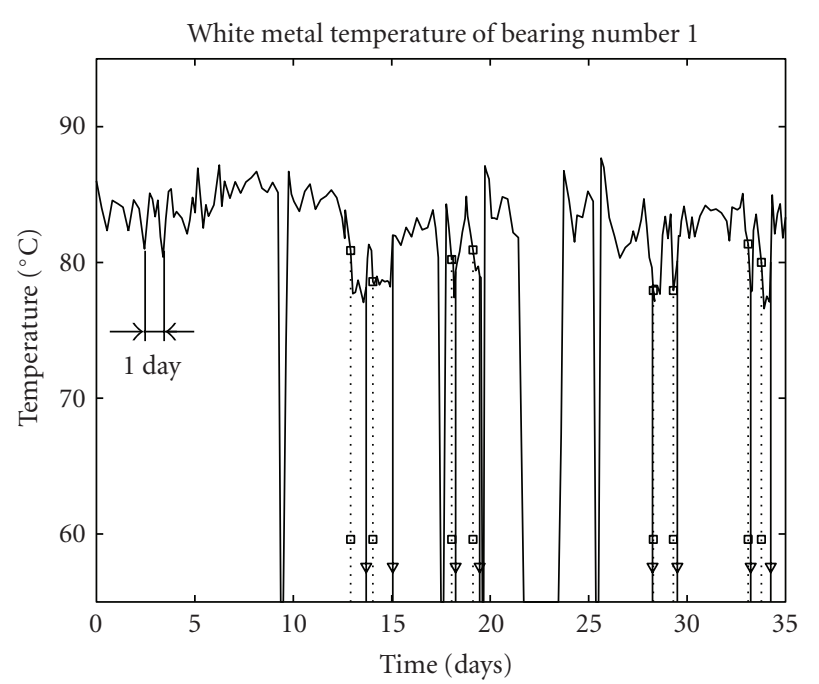

Instability onsets

- Beginning

$\nabla$ End

FIgURE 14: Historic trend of the temperature of the lower lobe of bearing no. 1 measured during a 35 days' period.

inside the bearing radial clearance, the harmonic order of the subsynchronous vibrations caused by the oil-whirl phenomena is rather close to $0.5 \mathrm{X}$. On the contrary, in the present case study the order of the subharmonic component was significantly lower and equal to $0.26 \mathrm{X}$.

However, when the shaft rotational speed is twice higher than the first flexural critical speed of the rotor the frequency of the dominant subharmonic component of the shaft vibration can be synchronised just with that of the first flexural critical speed of the shaft. In this case, since the destabilising forces generated in the fluid-film excite a resonance of the rotor system whose damping factor $h$ often becomes negative, the vibrations induced in the shaft-train can be unstable. In the literature, this phenomenon in called oil-whip instability $[2,9]$.

Sometimes, the transition from oil-whirl to oil-whip instability occurs during the machine startup $[2,5]$. However, instability phenomena can suddenly arise also at the constant operating speed of a rotating machine owing to particular effects caused in the journal bearings by changes of process and ambient parameters. In the present case

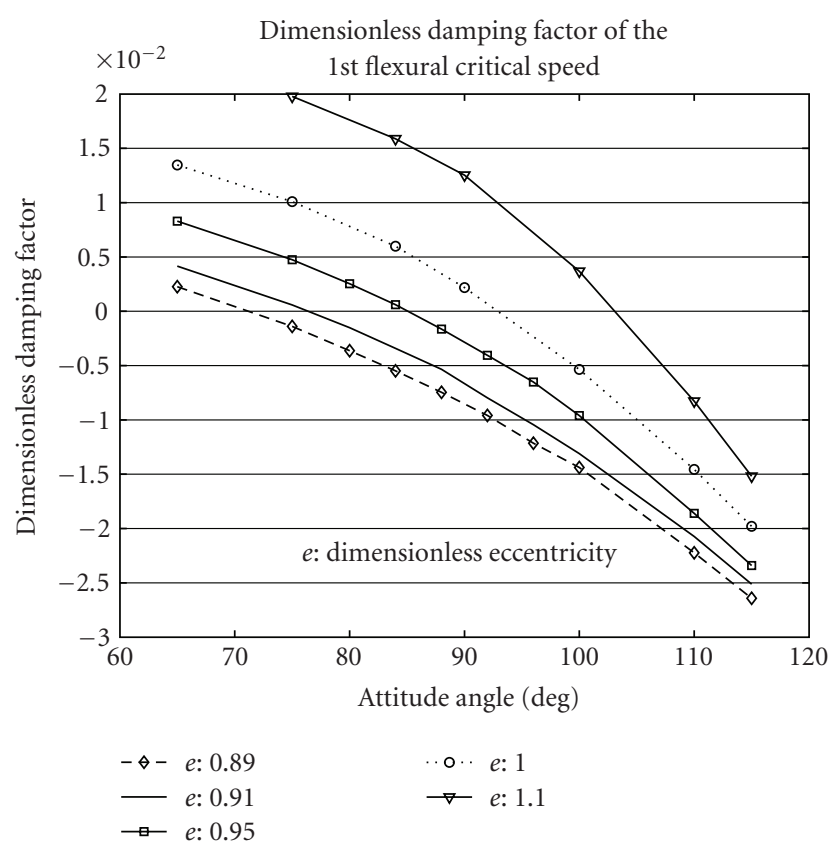

FIGURE 15: Influence of attitude angle and journal eccentricity ratio in bearing no. 1 on the dimensionless damping factor associated with the 1st flexural critical speed.

study, the rotational speed that corresponded to the subsynchronous vibration of the generator rotor $(780 \mathrm{rpm})$ was lower than both theoretical and experimental values of the first flexural critical speed of the shaft (nearly $845 \mathrm{rpm}$ ). At first this seemed to be an incongruence. In order to find more consistent reasons for the explanation of this malfunction of the power unit, further investigations were carried out.

The results obtained with model no. 3, which are presented below, clarify that the machine dynamic behavior was really influenced by oil-whip instability onsets.

It is well known that lightly loaded bearings can be affected by oil-whirl and oil-whip phenomena. Therefore, the available monitoring data that could point out the symptoms of a temporary light loading on bearing no. 1 were analysed. Figure 10 shows the shaft average centreline curves measured at this bearing during a startup and a rundown occurred at the end of an on-load operating period. The machine thermal state at the end of the startup, that is, at $3000 \mathrm{rpm}$, was quite different from that at the beginning of the 


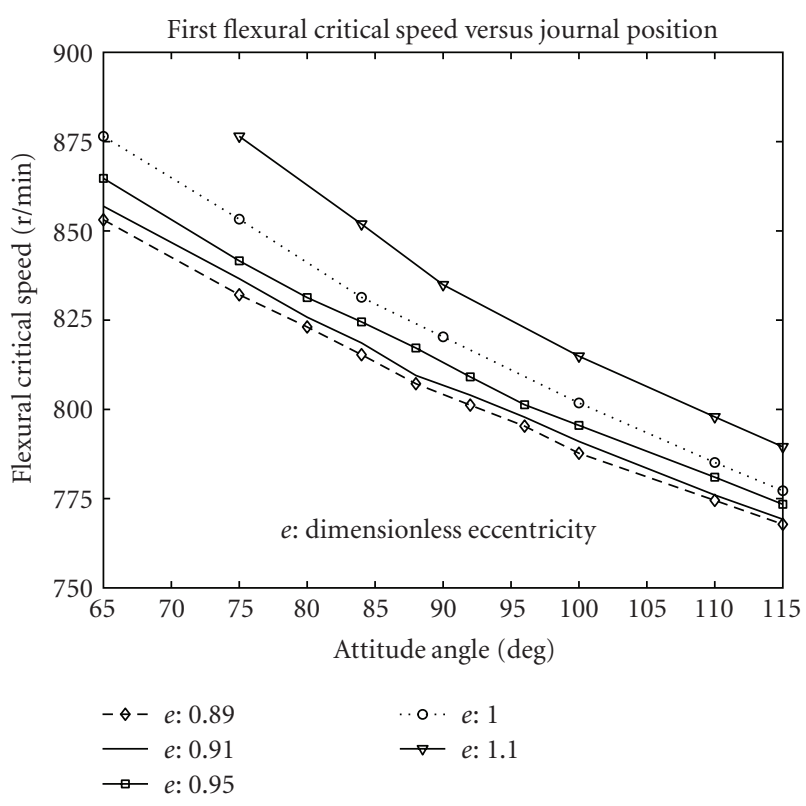

FIGURE 16: Influence of attitude angle and journal eccentricity ratio in bearing no. 1 on the 1st flexural critical speed of the shaft-train.

rundown. The temperature of shafts, casings, supports, and foundation structure can significantly affect the shaft-train alignment and bearing loads. The experimental shaft average centreline curves illustrated in Figure 10 are compared to the theoretical curve obtained by authors' integration of Reynolds equation and considering the nominal bearing load due to the reference hot alignment provided by the machine manufacturer.

Both cold and hot machine alignments caused a maximum vertical displacement of the journal, evaluated with respect to the bearing bottom, that was significantly higher than the corresponding theoretical value. This can be considered the consequence of an excessively light load acting on the generator bearing no. 1 due to an inaccurate static alignment or to an abnormal hot alignment of the shaft-train.

The historic trend of the gap data measured at bearing no. 1 during on-load operating conditions was analysed to study the changes of the dimensionless eccentricity of the journal that can be ascribed to changes in the machine hot alignment. Figure 11 shows the historic trend of magnitude and attitude angle of the dimensionless eccentricity of the journal inside bearing no. 1 over a four-day time window during which two instability phenomena and two speed transients occurred. Figure 11 shows that the eccentricity ratio was affected by significant changes in the operating condition. The instability phenomena began and continued for different values of the eccentricity ratio. Anyhow, the unstable subsynchronous vibrations occurred only for values of the attitude angle higher than $98^{\circ}$ degrees, that is, when the journal average position was in the upper part of the bearing. This confirmed the suspect that a decrease of the bearing loading at the support no. 1, due to changes of the machine hot alignment, caused the occurrence of the oilwhip instability onsets.
The polar plot illustrated in Figure 12 shows the same data reported in Figure 11. The end of the vectors that represent the journal position, expressed in polar coordinates, associated with a normal dynamic behaviour of the generator has been plotted with a dot. On the contrary, the journal positions associated with high unstable subsynchronous vibrations have been plotted with a square marker.

The data illustrated in Figure 12 show that the instability phenomena occurred when the journal average position at bearing no. 1 was characterised by amplitudes of the eccentricity ratio higher than 0.93 and by values of the attitude angle higher than $98^{\circ}$ degrees.

In order to validate these results and obtain further explanations for the occurrence of the instability onsets, the dynamic stiffness coefficients of bearing no. 1 were evaluated at $3000 \mathrm{rpm}$ considering a journal position defined by an eccentricity ratio equal to 0.93 and by an attitude angle equal to $96^{\circ}$ degrees: these values are very close to the limit values that caused instability onsets in the experimental dynamic behaviour. The calculated dynamic stiffness coefficients obtained with this case study were included into a further machine model denoted no. 3. The eigenvalues of this model were evaluated considering a rotational speed equal to $3000 \mathrm{rpm}$. The flexural critical speeds and the respective dimensionless modal damping factors associated with the imaginary and real parts, respectively, of the first five eigenvalues are shown in the last two columns of Table 3. These results can be compared to those obtained with models no. 1 and no. 2 .

The modal damping factor, $h_{1}$, associated with the first flexural critical speed of the generator rotor evaluated with the model no. 3 is negative. This is the mathematical condition for the occurrence of instability phenomena in the dynamic behaviour of the shaft-train. The excessively high vertical position of the journal inside bearing no. 1 caused a decrease of the average overall stiffness of the oilfilm. Owing to this, the value of the first flexural critical speed of the generator decreased up to $798 \mathrm{rpm}$, which corresponds to the harmonic order $0.266 \mathrm{X}$ evaluated with respect to the operating speed. This value is very close to the harmonic order of the experimental subsynchronous unstable vibrations $(0.26 \mathrm{X})$.

Therefore, the results of this model-based investigation indicate that the frequency of the noticeable subsynchronous vibrations of the generator that occasionally occurred in operating conditions almost coincides with the first natural frequency of the shaft, associated with the " $U$ " bending mode, evaluated at the operating speed. This behaviour is typical of oil-whip phenomena in rotating machines. That is, the occurrence of destabilising forces in the journal bearing no. 1 excited a normal mode of the rotor system that, in the machine model no. 3 , is associated with a complex eigenvalue whose real part is positive: this causes the condition for the occurrence of unstable vibrations. Owing to this, in the experimental behaviour, the frequency of the subsynchronous vibrations was almost synchronised with the first natural frequency of the generator rotor.

With regard to this, it is necessary to consider that the machine natural frequencies are influenced by the 

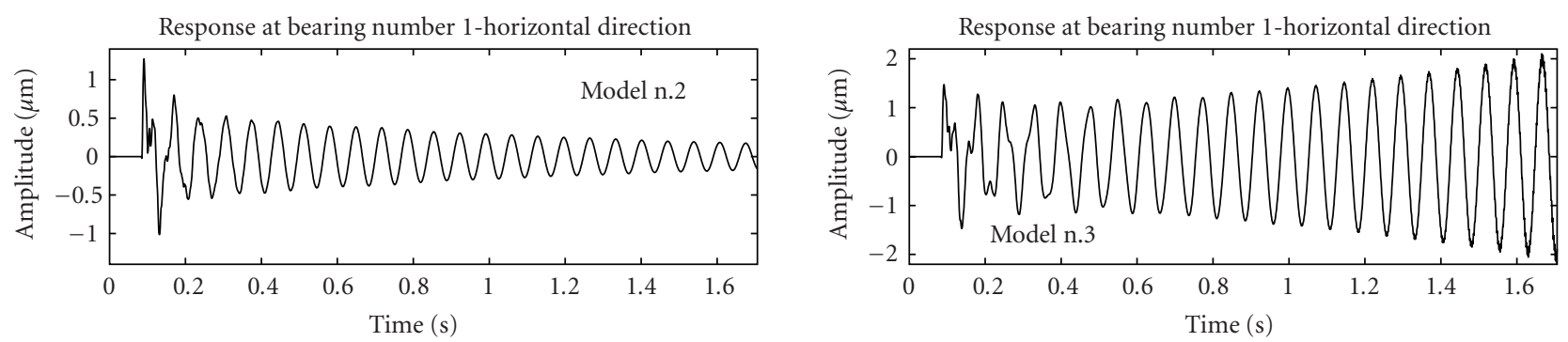

FIGURE 17: Impulse excitation response of the shaft evaluated at bearing no. 1 in the horizontal direction by means of models no. 2 and no. 3 .

speed-dependent values of the dynamic stiffness coefficients of the oil-film journal bearings as well as by the gyroscopic effects. Therefore, in order to simulate the instability phenomena that occurred in operating condition, in this study the machine eigenvalues and eigenmodes were evaluated at the operating speed.

In the present paper, the eigenmodes associated with the first four eigenvalues of the models no. 1 and no. 3 are not reported because they are very similar to those provided by the model no. 2 (Figure 9). This result is not surprising as the models no. 2 and no. 3 were obtained by partially refining the model no. 1 . This tuning process significantly improved the model accuracy and allowed the instability phenomena to be simulated but it caused only minor changes of the natural frequencies and normal modes of the rotor system.

The results of this first investigation suggested to perform a careful analysis of the journal average position within bearing no. 1, with the unit in operating condition, looking for the occurrence of significant changes of the machine hot alignment that caused high values of eccentricity ratio and attitude angle. Figure 13 shows the historic trend of the overall amplitude of the shaft vibrations measured on bearing no. 1, at the operating speed, during a 35-day period. The high and evident peaks of the amplitude curve show the occurrence of oil-whip instability onsets, which caused a considerable increase of the level of the $0.26 \mathrm{X}$ harmonic order of the shaft vibrations. Sometimes these unstable vibrations were required to do a machine rundown but in general the oil-whip phenomena were automatically extinguished after few hours without doing any specific change in significant process parameters.

A more accurate analysis of the monitoring data collected by the supervisory system of the plant showed that every oilwhip instability onset was preceded by an evident decrease of the temperature of the white metal of the lower lobe of bearing no. 1. The historic trend of this temperature, measured during the same period considered to plot the vibrations illustrated in Figure 13, is shown in Figure 14. Within this monitoring period the oil temperature measured at the inlet of the generator journal bearings no. 1 and no. 2, here not documented for the sake of brevity, was nearly constant. Every time the temperature of bearing no. 1 decreased below $80^{\circ} \mathrm{C}$, subharmonic vibrations $(0.26 \mathrm{X})$, whose amplitude quickly increased, were generated.

In occasion of these phenomena, the journal eccentricity ratio and attitude angle within bearing no. 1 approached values close to 0.98 and $98^{\circ}$ degrees, respectively. It is possible to suppose that the decrease of the bearing temperature was the consequence of a decrease of the bearing load due to a change of the machine hot alignment. In accordance with the supposition of the presence of a not ideal hot alignment, the maximum temperature of the outboard bearing (no. 2) of the generator was about $15^{\circ} \mathrm{C}$ degrees higher than that of the inboard bearing (no. 1) although the geometrical parameters of these two journal bearings and the respective loads were nearly the same. This can be the symptom of a machine misalignment.

Anyhow a weak sensitivity of machine casings, supports, and foundations to the unit thermal state is not unusual. In the present case study, the temperature of the cabinet that contained the power unit was controlled by a set of fans, whose nominal flow showed to be a little underestimated in comparison to the plant requirements. The high air temperature that often occurs in summertime in the south of Italy, where this power plant is sited, makes the sensitivity of the vibrations of this machine to its thermal state more critical. Therefore, depending on the meteorological conditions, the temperature inside the cabinet occasionally reached considerable values. It is possible to suppose that this temperature influenced the machine hot alignment causing occasional critical conditions for the generation of unstable subsynchronous vibrations.

The first part of the curve illustrated in Figure 14 shows some evident daily decreases of the bearing temperature which approached a lower level close to $80^{\circ} \mathrm{C}$ degrees. This confirms that the external air temperature, and then the air temperature inside the cabinet, influenced the machine alignment and bearing temperature. After mid autumn, when mean and maximum daily temperature of the air decreased, the oilwhip instability onsets never again occurred. Some months later, in occasion of the next planned maintenance of the unit, specific measurements of the alignment between generator and gas turbine showed the necessity to correct the machine cold alignment by assigning an upward displacement of the support no. 1. This action increased the bearing load both in cold and hot thermal states of the unit.

\section{Model-Based Sensitivity Analysis}

In order to consider marginal uncertainties that affect the evaluation of the journal average position inside the bearing, 


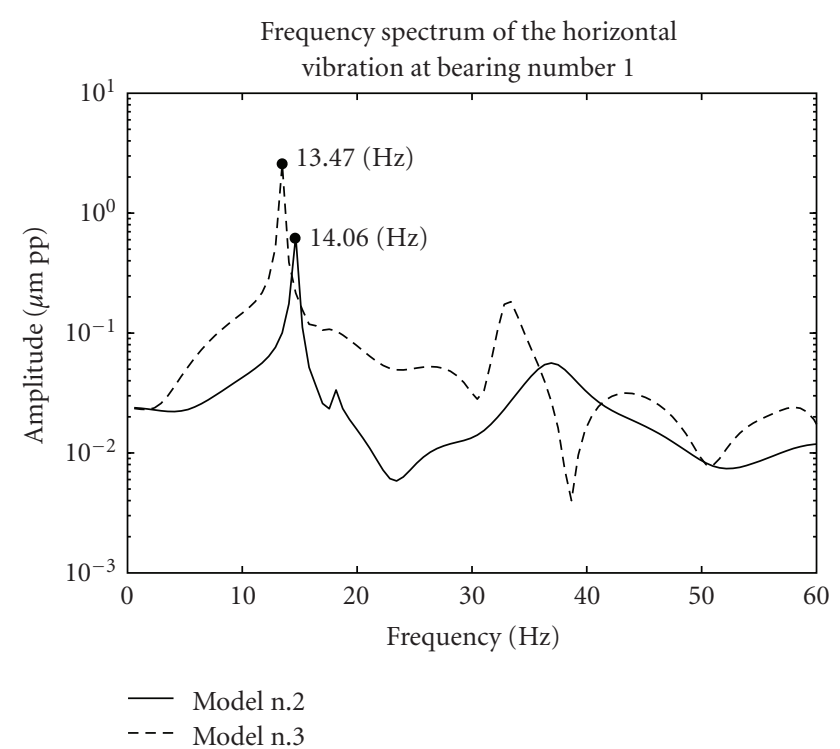

FIGURE 18: Frequency spectrum of the impulse excitation responses evaluated at bearing no. 1 by means of the models no. 2 and no. 3 .

obtained by processing gap experimental data, a modelbased technique was used to perform a parametric analysis. This study allowed the effects of the journal average position on the oil-film dynamic stiffness evaluated at $3000 \mathrm{rpm}$ to be investigated. Moreover, the nonlinear relationship between the oil-film dynamic stiffness and the dimensionless damping factor associated with the fist flexural critical speed of the generator was studied. Therefore, the relationship between the journal average position and the value of the above-mentioned damping factor $h_{1}$ was investigated. The results of this study are shown in Figure 15.

A significant increase of the attitude angle as well as a decrease of the dimensionless eccentricity causes changes in the oil-film geometry and in particular in its minimum height. This causes a reduction of the overall dynamic stiffness of the bearing. Owing to this, the damping factor $h_{1}$ can become negative. As above said, in operating conditions, the journal average position inside the bearing can be influenced by changes in the shaft-train alignment due to variations of the machine thermal state.

Figure 16 shows the influence of attitude angle and eccentricity ratio on the first flexural critical speed of the shaft-train, whose normal mode mainly affects the transverse vibrations of the generator rotor.

The results illustrated in this figure were obtained by changing only the journal average position inside bearing no. 1 . The couples of values of eccentricity ratio and attitude angle that caused a negative damping factor $h_{1}$ also caused a decrease of the first flexural critical speed of the generator from the respective reference value, calculated considering a normal hot alignment of the shaft-train. This behaviour is in accordance with the experimental evidences.

The results of the eigenvalue analysis showed that some critical machine alignments could cause the mathematical condition for the occurrence of unstable vibrations of the generator rotor. However, a perturbation of the steady state response of the rotor system, for example, caused by oil-film destabilising forces generated in journal bearings, excites further system normal modes in addition to that corresponding to the first critical speed of the generator rotor. Dissipative and nondissipative forces are associated with the system eigenvalues whose real part is negative and positive, respectively. Therefore, in the critical alignment condition, the vibrations caused by a system perturbation generate dissipative forces, whose effects can overcome those due to the nondissipative forces, due to the excitation of the first balance resonance of the generator with a negative modal damping factor.

\section{Stability Analysis}

The accurate study of the stability of the machine response is a nonlinear problem that would require to consider the initial conditions for the integration of the motion equations of the rotor system in the time domain. Anyhow a simple analysis performed by means of an approximated method allowed interesting results to be obtained. The response caused by an impulse perturbation applied to the FEM of the machine-train in the cross-section of the generator reported in Figure 8 was evaluated with the shaft rotating at the operating speed. This force excited several normal modes of the generator rotor.

The machine models no. 2 and no. 3, which simulate the ideal and critical hot alignment, respectively, were used for this study. Figure 17 shows the time-base plot of the shaft vibration, caused by the impulse excitation, evaluated at bearing no. 1 in the horizontal direction by means of the above-mentioned models. Both responses are dominated by the contribution of the excitation of the normal mode associated with the first flexural critical speed of the generator rotor. The response obtained with the model no. 3 is expansive.

This confirms that when the real part of the first eigenvalue became positive the effects of the nondissipative forces generated in the system can overcome the effects due to the dissipative damping forces associated with the other eigenvalues of the system whose real part is negative. Figure 18 shows the frequency spectrum of the two vibration time histories illustrated in Figure 17.

Owing to the decrease of the stiffness coefficients of the oil-film caused by the decrease of the load acting on bearing no. 1 , the first natural frequency of the shaft decreased from 14.06 Hz to $13.47 \mathrm{~Hz}$. In operating conditions, this frequency corresponds to the that of the harmonic order $0.269 \mathrm{X}$. These results are in good accordance with the experimental evidence and explain the reason for the occurrence of the oil-whip instability onsets that generated high $0.26 \mathrm{X}$ subsynchronous vibrations.

\section{Conclusions}

The occurrence of subsynchronous vibrations caused by oil-whip instability onsets is one of the most critical malfunctions that can affect the dynamic behaviour of rotating 
machines. Investigation methods based on models of oil-film journal bearings and shaft-train can be very useful to study the sensitivity of the machine vibrations to the occurrence of oil-whip instability onsets generated by light bearing loads and abnormal hot alignments of the shaft-train.

In this paper, the successful results obtained by combining model-based diagnostic techniques with detailed analyses of monitoring data aimed to point out and investigate the effects of oil-whip instability onsets on the vibrations of rotating machines are shown and discussed. The dynamic behaviour of a power unit whose shaft-train alignment showed to be influenced by the machine thermal state has been analysed. The results provided by the model-based investigation method explained the reasons of the occurrence of very high subsynchronous vibrations that were detected in operating condition on the generator supports. The influence of the average journal position on the dynamic stiffness coefficients of the oil-film journal bearings of the generator was studied. Moreover, the effects of the bearing coefficients on the values of real and imaginary components of the eigenvalues of the machine model have been investigated.

This study confirmed that owing to critical hot alignment conditions experienced in the on-load running state the real part of the eigenvalue associated with the first flexural critical speed of the generator rotor became positive in accordance with the occurrence of oil-whip instability onsets pointed out by the experimental vibration data.

The diagnostic strategy used for this case study has shown the good capabilities of model-based diagnostic techniques also in the case of the analysis of not trivial problems that can affect the dynamic behaviour of large rotating machines.

\section{References}

[1] J. W. Lund and E. Saibel, "Oil whip whirl orbits of a rotor in sleeve bearings," ASME Transactions, vol. 89, no. 4, 1967.

[2] A. Muszyńska, "Whirl and whip-rotor/bearing stability problems," Journal of Sound and Vibration, vol. 110, no. 3, pp. 443$462,1986$.

[3] J. M. Vance, Rotordynamics of Turbomachinery, John Wiley \& Sons, New York, NY, USA, 1988.

[4] T. Yamamoto and Y. Ishida, Linear and Nonlinear Rotordynamics, John Wiley \& Sons, New York, NY, USA, 2001.

[5] B. Schweizer, "Oil whirl, oil whip and whirl/whip synchronization occurring in rotor systems with full-floating ring bearings," Nonlinear Dynamics, vol. 57, no. 4, pp. 509-532, 2009.

[6] A. El-Shafei, S. H. Tawfick, M. S. Raafat, and G. M. Aziz, "Some experiments on oil whirl and oil whip," Journal of Engineering for Gas Turbines and Power, vol. 129, no. 1, pp. 144-153, 2007.

[7] E. Capone, "Oil whirl in journal bearings under no load conditions," Wear, vol. 26, no. 2, pp. 207-217, 1973.

[8] M. A. C. Michalski, M. Zindeluk, and R. O. Rocha, "Nonlinear experimental detection of oil whirl in horizontal rotors," in Advances in Vibration Control and Diagnostics, N. Bachschmid and P. Pennacchi, Eds., p. 30, Polimetrica International Publisher, Monza, Italy, 2006.
[9] D. W. Childs, Turbomachinery Rotordynamics-Phenomena, Modeling and Analysis, John Wiley \& Sons, New York, NY, USA, 1993.

[10] D. E. Bently and A. Muszyńska, "Role of circumferential flow in the stability of fluid-handling machine rotors," in Proceedings of the 5th Workshop on Rotordynamic Instability Problems in High-Performance Turbomachinery, vol. 3026, pp. 415-430, Texas A\&M University, 1988, NASA CP.

[11] A. Muszyńska and D. E. Bently, "Frequency-swept rotating input perturbation techniques and identification of the fluid force models in rotor/bearing/seal systems and fluid handling machines," Journal of Sound and Vibration, vol. 143, no. 1, pp. 103-124, 1990.

[12] A. Muszyńska, Rotordynamics, Taylor \& Francis Group-CRC Press book, New York, NY, USA, 2005.

[13] M. Lalanne and G. Ferraris, Rotordynamics Prediction in Engineering, John Wiley \& Sons, Chichester, UK, 2nd edition, 1988.

[14] M. L. Adams, jr., Rotating Machinery Vibration-From Analysis to Troubleshooting, Marcel Dekker, New York, NY, USA, 2001.

[15] A. Z. Szeri, Fluid Film Lubrication-Theory and Design, Cambridge University Press, Cambridge, UK, 1988.

[16] R. G. Kirk and E. J. Gunter, "Short bearing analysis applied to rotor dynamics. Part l: theory," American Society of Mechanical Engineers, vol. 98, no. 75, 1975.

[17] T. Someya, Journal-Bearing Databook, Springer, Berlin, Germany, 1989.

[18] G. W. Stachowiak and A. W. Batchelor, Engineering Tribology, Butterworth Heinemann, burlington, Vt, USA, 2005. 

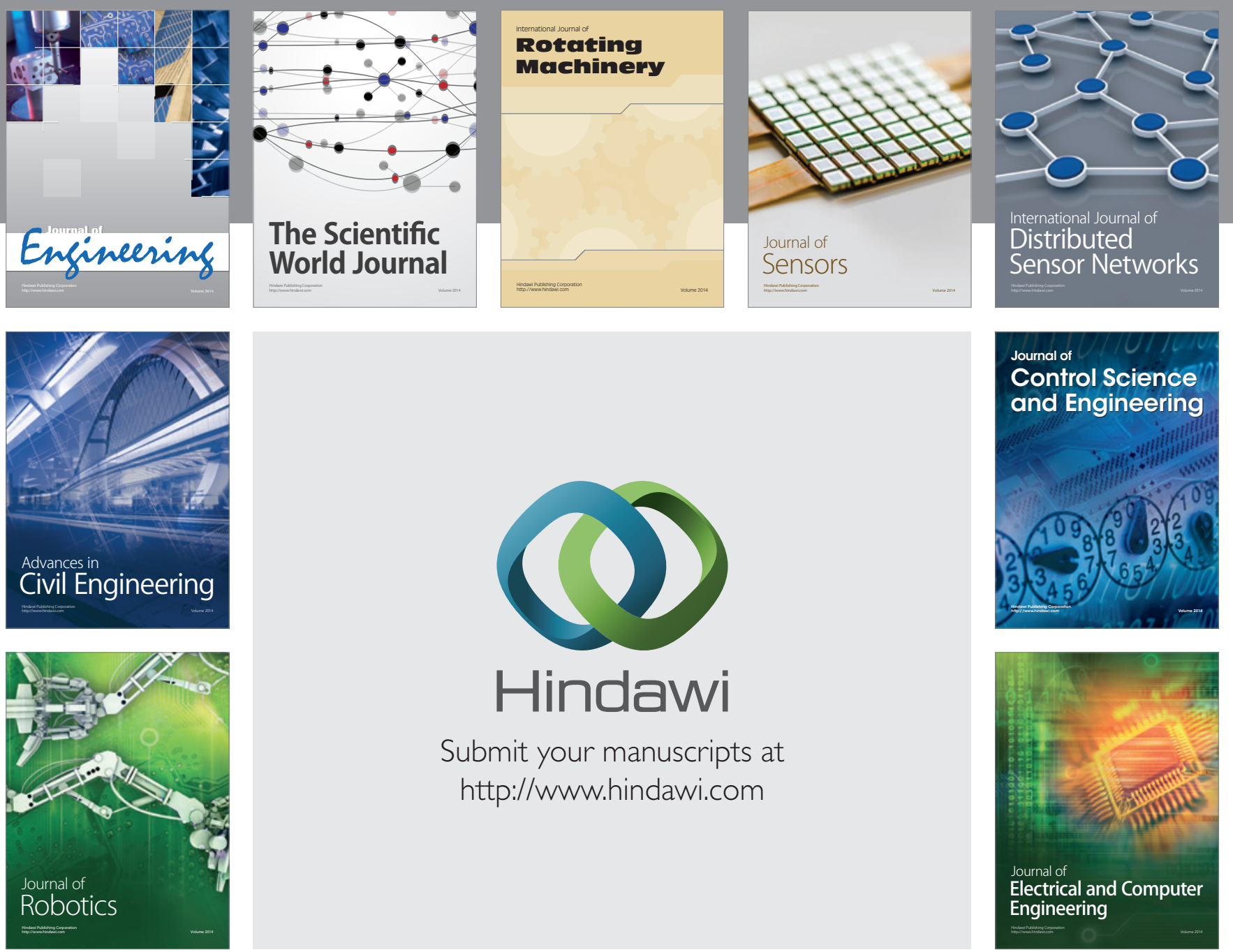

Submit your manuscripts at

http://www.hindawi.com
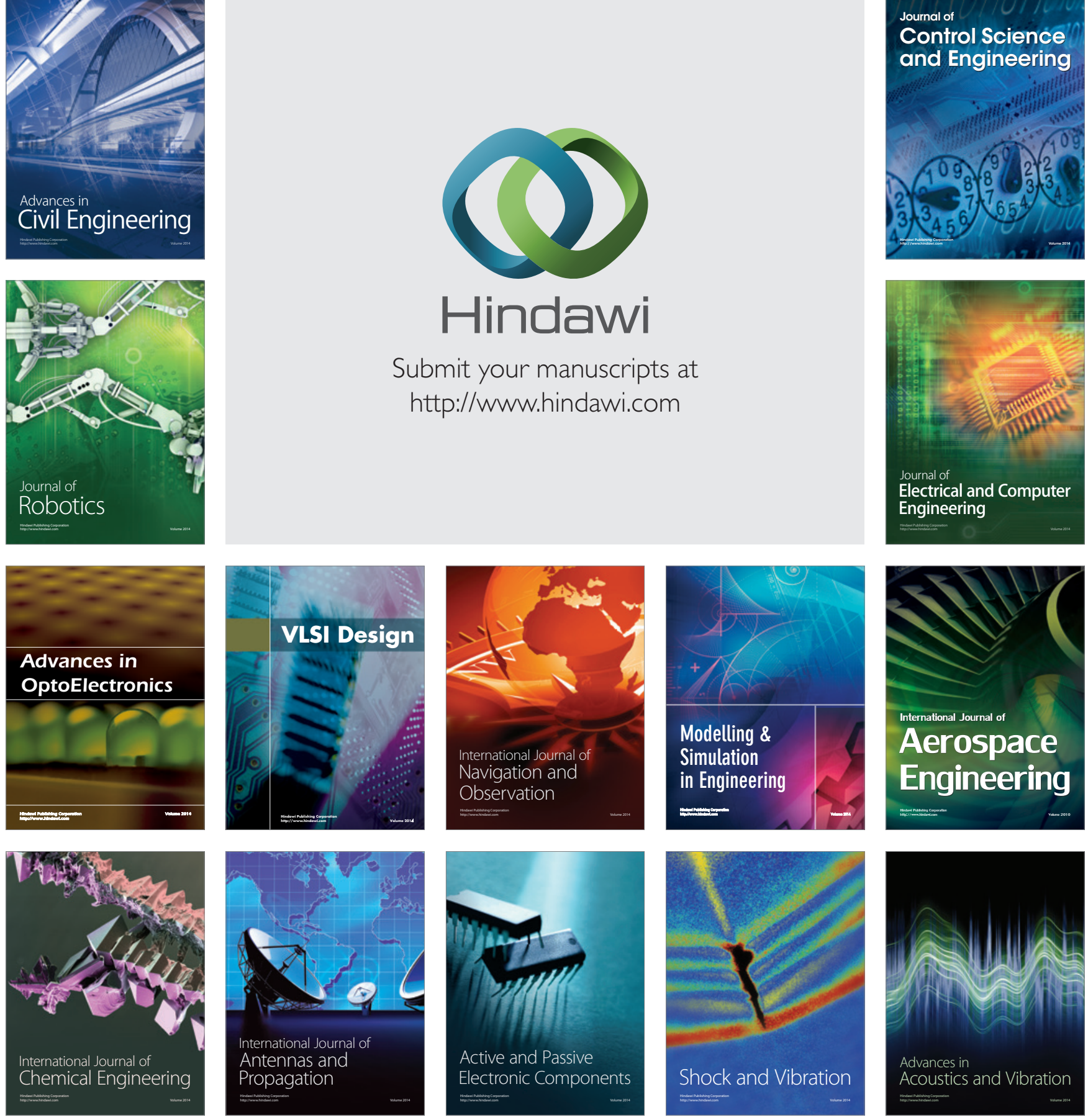